\title{
Pengaruh Daya Tarik Iklan di Konvergensi Media Terhadap Brand Awareness (Studi Iklan Tiket.com di YouTube Pada Kalangan Generasi Z di Jakarta)
}

\author{
Felicia Herlyana, Lusia Savitri Setyo Utami \\ feliciaherlyana@gmail.com,lusias@fikom.untar.ac.id \\ Fakultas Ilmu Komunikasi Universitas Tarumanagara
}

\begin{abstract}
The presence of social media increases technological progress. One of the most accessed social media is YouTube. Aside from being a means of entertainment, YouTube is now a means of promotion. One company that uses YouTube as a promotional tool is Tiket.com. Tiket.com is a company most often used by young people in Indonesia. Research on discussing the advertising appeal of Tiket.com on YouTube on brand awareness of $Z$ generation in Jakarta. This study aims to determine whether or not there is an influence of the attractiveness of advertisements on brand awareness and how much influence the attractiveness of advertisements on YouTube on brand awareness by using Tiket.com ads as research objects.. This research was conducted using quantitative survey methods. The population in this study was generation $Z$ in Jakarta who had watched Tiket.com advertisements on YouTube with a sample of 115 respondents. The conclusions of the study show that there is an influence of advertising appeal of Tiket.com on YouTube on brand awareness is strong and equal to 61,9\%, while the remaining $38,1 \%$ could be influenced by others factors.
\end{abstract}

Keywords: advertising appeal, brand awareness, Social Media, YouTube.

\begin{abstract}
Abstrak
Hadirnya media sosial meningkatkan kemajuan teknologi. satu media sosial yang banyak diakses adalah YouTube. Selain sebagai sarana hiburan, kini YouTube menjadi sarana promosi. Salah satu perusahaan yang menjadikan YouTube sebagai sarana promosi yaitu Tiket.com. Tiket.com merupakan perusahaan yang memberikan pelayanan reservasi tiket secara online yang menempati urutan kedua sebagai perusahaan tiket yang paling sering digunakan kalangan muda di Indonesia. Penelitian ini membahas tentang pengaruh daya tarik iklan Tiket.com di YouTube terhadap brand awareness generasi Z di Jakarta. Penelitian ini bertujuan untuk mengetahui apakah ada atau tidak pengaruh dari daya tarik iklan terhadap brand awareness dan seberapa besar pengaruh daya tarik iklan di YouTube terhadap brand awareness dengan menggunakan iklan Tiket.com sebagai objek penelitian. Penelitian ini dilakukan dengan pendekatan kuantitatif dengan metode survei. Populasi penelitian ini adalah generasi $\mathrm{Z}$ di Jakarta yang pernah menonton iklan Tiket.com di YouTube dengan sampel penelitian sebanyak 115 responden. Hasil kesimpulan penelitian menunjukkan bahwa terdapat pengaruh daya tarik iklan Tiket.com di YouTube terhadap brand awareness bersifat kuat dan sebesar $61,9 \%$, sedangkan sebanyak $38,1 \%$ dapat dipengaruhi oleh faktor-faktor lain.
\end{abstract}

Kata Kunci: Media Sosial, YouTube, Daya Tarik Iklan, Brand Awareness

\section{Pendahuluan}

Pada era sekarang ini, perkembangan teknologi internet sangat pesat sehingga masyarakat tentu tidak asing dengan internet. Internet merupakan wadah masyarakat 
untuk mencari informasi di dalam atau luar negeri. Selain mencari informasi, internet juga sebagai wadah komunikasi baik jarak dekat atau jarak jauh. Dengan adanya internet, mempermudah kita untuk melihat dunia luar. Kehadiran internet menambah banyak media sosial. Definisi media sosial dalam Rulli Nasrullah (2017) menurut Mandiberg (2012) adalah sebuah media yang mewadahi pengguna untuk menghasilkan konten. Kehadiran media sosial yang dapat diakses dengan mudah juga semakin banyak menambah platform media sosial yang ditawarkan.

Menurut data We Are Social (Januari 2019) ada beberapa media sosial yang sering digunakan masyarakat di Indonesia adalah YouTube, WhatsApp, Facebook, Instagram, Line dan Twitter. Salah satu media sosial yang mudah dan sering diakses masyarakat Indonesia adalah YouTube. YouTube merupakan bagian dari konvergensi media. Romli (2016) menjelaskan bahwa konvergensi media adalah gabungan dari layanan teknologi informasi serta komunikasi. YouTube dapat dikatakan sebagai konvergensi media karena platform media sosial tersebut memberi kemudahan masyarakat dalam penyampaian komunikasi dan informasi.

YouTube adalah situs web milik Google yang dapat mengunggah video secara gratis. Selain menjadi sarana hiburan, YouTube juga digunakan sebagai sarana promosi. Dengan penggunaan YouTube yang marak digunakan masyarakat Indonesia terutama kalangan muda, YouTube menjadi sarana promosi yang paling tepat untuk menargetkan kalangan muda sebagai target utama perusahaan.

Salah satu perusahaan yang menjadikan YouTube sebagai sarana promosi adalah Tiket.com. Iklan Tiket.com hadir di YouTube untuk menimbulkan kesadaran merek Tiket.com pada masyarakat terutama kalangan muda yang menonton YouTube.

Perumusan masalah dalam penelitian yaitu apakah ada pengaruh atau tidak dan kuat atau tidak daya tarik iklan Tiket.com di YouTube terhadap brand awareness generasi Z di Jakarta. Dijelaskan bahwa generasi Z dapat mengaplikasikan seluruh kegiatan dalam waktu bersamaan (multi tasking).

Di dalam buku Priansa (2017), Kotler dan Keller (2012) mendefinisikan brand awareness adalah kemampuan konsumen mengidentifikasikan sebuah merek dalam kondisi yang berbeda yang tercermin oleh pengenalan atau pengingatan merek.

Dalam jurnal Jennifer dan Sari (2018) menjelaskan bahwa brand awareness tidak mengharuskan konsumen hanya mengenal dan mengingat namanya saja, tetapi ada sesuatu yang dapat memicu hal tersebut. Hal tersebut dapat dipicu melalui iklan yang menarik konsumen.

Rita \& Saliman (2001) dalam jurnal Legasari, Indarti dan Restuti (2013) mendefinisikan daya tarik iklan adalah kemampuan sebuah iklan untuk menarik perhatian target sasaran. Iklan Tiket.com yang hadir di YouTube dengan konsep unik, menarik, dan mudah diingat dapat meningkatkan kesadaran masyarakat akan merek Tiket.com.

\section{Metode Penelitian}

Pada penelitian ini digunakan metode kuantitatif eksplanasi dengan menggunakan survei. Survei yang dilakukan dengan menyebarkan kuesioner. Penyebaran kuesioner dilakukan dengan menggunakan teknik purposive sampling. Populasi yang digunakan dalam penelitian ini adalah generasi $\mathrm{Z}$ di Jakarta. Untuk dapat menentukan jumlah sampel, peneliti menggunakan teori Ferdinand (2005) dalam jurnal Hanum dan Utami (2010) jumlah sampel adalah 5 - 10 dikali dengan jumlah 
indikator pada penelitian. Dalam penelitian ini, indikatornya sebanyak 23, sehingga jumlah sampel yang diambil dalam penelitian ini adalah 115 responden.

Variabel independen atau bebas yaitu Daya Tarik Iklan (X) yang dibangun dengan teori dimensi menggunakan Rita \& Saliman (2001) dalam jurnal Legasari, Indarti dan Restuti (2013), yaitu memiliki makna (meaningful), berbeda (distinctive) dan dapat dipercaya (believable). Variabel dependen atau terikat yaitu brand awareness (Y) yang dibangun dengan teori dimensi menggunakan Priansa (2017), yaitu tidak menyadari merek (unware brand), pengenalan merek (brand recognition), pengingatan kembali terhadap merek (brand recall) dan puncak pikiran (top of mind).

Dalam pengumpulan data, peneliti memilih teknis dengan menyebarkan angket atau kuesioner secara online dengan menggunakan google form. Data primer pada penelitian ini menggunakan kuesioner yang diisi para penonton iklan Tiket.com di YouTube, sedangkan data sekunder pada penelitian ini melalui sumber buku dan sumber jurnal yang membahas tentang hal yang sama dengan penelitian ini. Teknik skala yang digunakan pada penelitian ini yaitu teknik skala likert 1-5. Teknik analisis data dan pengolahan data yang digunakan peneliti adalah analisis uji koefisien korelasi, koefisien determinasi, regresi linear sederhana, dan uji T. Teknik keabsahan datanya adalah uji validitas, reliabilitas dan normalitas.

\section{Hasil Penemuan dan Diskusi}

Pada penelitian ini, peneliti melakukan analisis terhadap dua variabel, yaitu variabel Daya Tarik Iklan (X) dan variabel Brand Awareness (Y). Berikut ini adalah hasil uji validitas, reliabilitas, normalitas, koefisien korelasi, koefisien determinasi, uji analisis regresi linear sederhana dan uji T dengan menggunakan software SPSS 15.

Tabel 1. Hasil Uji Validitas Daya Tarik Iklan (X)

\begin{tabular}{ccc}
\hline Variabel X & $\begin{array}{c}\text { Score } \text { Corrected Item } \\
\text { Total }\end{array}$ & Keterangan \\
\hline DTI1 & 0,659 & Valid \\
\hline DTI2 & 0,684 & Valid \\
\hline DTI3 & 0,747 & Valid \\
\hline DTI4 & 0,762 & Valid \\
\hline DTI5 & 0,727 & Valid \\
\hline DTI6 & 0,752 & Valid \\
\hline DTI7 & 0,770 & Valid \\
\hline DTI8 & 0,786 & Valid \\
\hline DTI9 & 0,819 & Valid \\
\hline DTI10 & 0,827 & Valid \\
\hline DTI1 & 0,752 & Valid \\
\hline DTI12 & 0,803 & Valid \\
\hline
\end{tabular}

Sumber: Pengolahan Data SPSS 15

Tabel 2. Hasil Uji Validitas Brand Awareness (Y)

\begin{tabular}{ccc}
\hline Variabel X & $\begin{array}{c}\text { Score Corrected Item } \\
\text { Total }\end{array}$ & Keterangan \\
\hline BA1 & 0,414 & Valid \\
\hline BA2 & 0,514 & Valid \\
\hline BA3 & 0,645 & Valid \\
\hline BA4 & 0,676 & Valid \\
\hline
\end{tabular}




\begin{tabular}{ccc}
\hline BA5 & 0,731 & Valid \\
\hline BA6 & 0,593 & Valid \\
\hline BA7 & 0,621 & Valid \\
\hline BA8 & 0,791 & Valid \\
\hline BA9 & 0,734 & Valid \\
\hline BA10 & 0,669 & Valid \\
\hline \multicolumn{2}{c}{ Sumber: Pengolahan Data SPSS 15}
\end{tabular}

\section{Uji Validitas}

Uji validitas dilakukan untuk mengukur tidak atau valid suatu pernyataan. Uji validitas dilakukan dengan 0,2 sebagai sebuah patokan terhadap kolom Score Corrected Item Total. Berdasarkan tabel 1 dan 2, hasil uji validitas lebih besar dari 0,2 maka hasil uji variabel $\mathrm{X}$ dan $\mathrm{Y}$ dinyatakan seluruhnya valid.

Tabel 3. Hasil Uji Reliabilitas

\begin{tabular}{ccc}
\hline Variabel & Nof items & $\begin{array}{c}\text { Cronbach's } \\
\text { Alpha }\end{array}$ \\
\hline Daya Tarik Iklan & 12 & 0,948 \\
Brand Awareness & 10 & 0,889 \\
\hline
\end{tabular}

Sumber: Pengolahan Data SPSS 15

\section{Uji Reliabilitas}

Variabel dinyatakan reliabel apabila nilai $\left(\mathrm{r}_{11}\right)>0,6$ (Siregar, 2013). Hasil uji reliabilitas menunjukkan bahwa semua pertanyaan variabel $\mathrm{X}$ dan Y dikatakan reliabel karena nilai Cronbach's Alpha lebih dari 0,6.

\section{Uji Normalitas}

Setelah dilakukan uji normalitas, peneliti mendapatkan nilai signifikansi sebesar 0,056 untuk variabel X dan 0,021 untuk variabel Y. berdasarkan hasil tersebut, maka variabel $X$ dinyatakan normal karena nilai signifikansi $0,056>0,05$ dan untuk variabel Y dinyatakan tidak normal karena nilai signifikansi $0,021<0,05$.

Tabel 4. Hasil Analisis Koefisien Korelasi

\begin{tabular}{ccccc}
\hline Model & $\mathrm{R}$ & R Square & $\begin{array}{c}\text { Adjusted R } \\
\text { Square }\end{array}$ & $\begin{array}{l}\text { Std. Error of } \\
\text { the Estimate }\end{array}$ \\
\hline 1 &, $787(\mathrm{a})$ &, 619 &, 615 & 4,52430 \\
\hline
\end{tabular}

Sumber: Pengolahan Data SPSS 15

\section{Uji Koefisien Korelasi}

Berdasarkan perhitungan di atas, nilai koefisien korelasi yang diperoleh sebesar 0,787. Karena hasilnya berada di interval 0,60-0,79 yang artinya daya tarik iklan memiliki hubungan yang kuat terhadap brand awareness generasi $\mathrm{Z}$ di Jakarta.

Tabel 5. Hasil Analisis Koefisien Determinasi

\begin{tabular}{clrrr}
\hline Model & R & R Square & $\begin{array}{c}\text { Adjusted R } \\
\text { Square }\end{array}$ & $\begin{array}{c}\text { Std. Error of } \\
\text { the Estimate }\end{array}$ \\
\hline 1 &, $787($ a) &, 619 &, 615 & 4,52430 \\
\hline \multicolumn{4}{c}{ Sumber: Pengolahan Data SPSS 15 }
\end{tabular}


Felicia Herlyana, Lusia Savitri Setyo Utami: Pengaruh Daya Tarik Iklan di Konvergensi Media Terhadap Brand Awareness (Studi Iklan Tiket.com di YouTube Pada Kalangan Generasi Z di Jakarta)

\section{Uji Koefisien Determinasi}

Berdasarkan hasil penelitian di atas, diketahui nilai koefisien determinasi adalah 0,619. Dalam hal ini menyatakan variabel $\mathrm{X}$ dapat menjelaskan terhadap variabel Y sebanyak 61,9\%, sedangkan sisanya sebanyak 38,1\% yang dijelaskan oleh variabel lainnya.

Tabel 6. Hasil Analisis Regresi Linear Sederhana

\begin{tabular}{llllllr}
\hline & & \multicolumn{2}{c}{$\begin{array}{c}\text { Unstandardized } \\
\text { Coefficients }\end{array}$} & $\begin{array}{c}\text { Standardized } \\
\text { Coefficients }\end{array}$ & $\mathrm{t}$ & \multicolumn{1}{c}{ Sig. } \\
Model & & $\mathrm{B}$ & Std. Error & Beta & \multicolumn{1}{c}{ B } & Std. Error \\
\hline 1 & $\begin{array}{l}\text { (Constant) } \\
\text { Daya } \\
\text { Tarik }\end{array}$ & 8,196 & 2,831 & & 2,895 &, 005 \\
& Iklan &, 677 &, 050 &, 787 & 13,543 &, 000 \\
& & & & & & \\
\hline
\end{tabular}

Sumber: Pengolahan Data SPSS 15

\section{Uji Regresi Sederhana}

Dari hasil tabel di atas, didapatkan persamaan regresi sederhana, yaitu:

Dari tabel di atas, didapatkan persamaan regresi sederhana, yaitu:

$\mathrm{Y}=\mathrm{a}+\mathrm{bX}$

$Y=8,196+0,677 X$

Berdasarkan perhitungan di atas, konstanta sebesar 8,196 yang memiliki arti nilai konsisten variabel brand awareness sebesar 8,196. Sedangkan koefisien regresi $\mathrm{X}$ sebesar 0,677 yang menyatakan setiap penambahan $1 \%$ nilai daya tarik iklan, maka nilai brand awareness bertambah sebanyak 8,196. Koefisien regresi bernilai positif, sehingga diartikan bahwa arah pengaruh variabel $\mathrm{X}$ terhadap variabel $\mathrm{Y}$ adalah positif. Hal ini dinyatakan bahwa semakin memiliki daya tarik iklan maka brand awareness generasi $\mathrm{Z}$ akan turut meningkat.

Tabel 7. Hasil uji T

\begin{tabular}{lllrrrl}
\hline \multirow{2}{*}{ Model } & & Sum of & & & & \\
& & Squares & df & Mean Square & F & Sig. \\
\hline 1 & Regression & 3754,501 & 1 & 3754,501 & 183,421 &, $000($ a) \\
& Residual & 2313,030 & 113 & 20,469 & & \\
\cline { 2 - 6 } & Total & 6067,530 & 114 & & & \\
\cline { 2 - 6 } & \multicolumn{5}{c}{ Sumber: Pengolahan Data SPSS 15 }
\end{tabular}

\section{Uji T (T-Test)}

Berdasarkan perhitungan di atas, nilai Sig. sebesar 0,000 yang artinya apabila sig $<0,05$ maka Ha diterima. Berarti dari hasil diatas didapatkan kesimpulan bahwa variabel $\mathrm{X}$ berpengaruh secara signifikan terhadap variabel $\mathrm{Y}$ (daya tarik iklan Tiket.com di YouTube terhadap brand awareness).

\section{Analisis}

Pada penelitian ini, peneliti menggunakan dua variabel, yaitu variabel Daya Tarik Iklan (X) dan variabel Brand Awareness (Y). dengan melihat hasil uji T-Test di antara variabel $\mathrm{X}$ dan $\mathrm{Y}$ menunjukkan hasil yang baik, yaitu Daya Tarik Iklan (X) Tiket.com di YouTube memiliki pengaruh terhadap Brand Awareness (Y) generasi Z 
di Jakarta. Hal ini sesuai dengan Hipotesis peneliti, yaitu terdapat pengaruh daya tarik iklan Tiket.com di YouTube terhadap brand awareness generasi Z di Jakarta. Artinya, semakin tinggi tingkat makna, perbedaan dan dapat dipercaya sebagai dimensi dari iklan Tiket.com di YouTube, maka semakin tinggi pengaruh terhadap brand awareness.

Melihat hasil koefisien determinasi, diketahui bahwa pengaruh Daya Tarik Iklan (X) terhadap Brand Awareness adalah 61,9\% dan 38,1\% yang dipengaruhi oleh variabel-variabel lain. Dengan demikian, dapat disimpulkan bahwa daya tarik iklan Tiket.com di YouTube berpengaruh terhadap generasi $\mathrm{Z}$ di Jakarta.

Berdasarkan hasil data di atas, hasil analisis dapat dikatakan pengaruh dimensi makna dengan brand awareness menunjukkan bahwa makna iklan Tiket.com di YouTube ingin menyampaikan informasi produk/jasa berpengaruh terhadap brand awareness generasi $\mathrm{Z}$ di Jakarta. Hasil penelitian ini didukung oleh pernyataan Morissan (2019) daya tarik iklan bertujuan untuk membujuk target pelanggan agar membeli karena produk yang bersangkutan adalah produk terbaik yang dapat memenuhi kebutuhan pelanggan. Pengaruh dimensi berbeda dengan brand awareness menunjukkan iklan Tiket.com di YouTube memiliki visual yang menarik dan kreatif dari iklan kompetitor lain sehingga berpengaruh terhadap brand awareness generasi $\mathrm{Z}$ di Jakarta. Hasil penelitian ini didukung oleh pernyataan Aaker (1997) dalam buku Priansa menyatakan merek berkaitan dengan kemampuan untuk dapat mengingat atau dapat mengenal kembali merek. Pengaruh dimensi dipercaya menggunakan kalimat yang jelas sehingga iklan tersebut dapat dipercaya oleh konsumen dan mempengaruhi brand awareness generasi $\mathrm{Z}$ di Jakarta. Hasil penelitian ini didukung oleh pernyataan Morissan (2019) yaitu suatu daya tarik iklan merupakan suatu yang menggerakkan khalayak mengenai keinginan dan membangkitkan ketertarikan.

\section{Kesimpulan}

Hasil uji koefisien korelasi menunjukkan bahwa daya tarik iklan berpengaruh kuat terhadap brand awareness generasi Z di Jakarta. Hasilnya menunjukan 0,787. Hasil pengujian hipotesis dalam penelitian ini, menunjukkan bahwa daya tarik iklan berpengaruh secara signifikan terhadap brand awareness generasi $\mathrm{Z}$ di Jakarta, yang bisa dilihat dari hasil uji $\mathrm{T}$ dengan nilai $0,000<0,005$. Berdasarkan kesimpulan tersebut, iklan Tiket.com belum mencapai pengaruh sangat kuat sehingga agar kedepannya diperhatikan lebih daya tarik iklan Tiket.com di YouTube untuk meningkatkan brand awareness, namun sebaiknya perlu diperhatikan hal-hal yang memicu daya tarik iklan agar kedepannya dapat lebih berpengaruh secara signifikan terhadap brand awareness Tiket.com di YouTube pada kalangan generasi Z di Jakarta dan agar dapat lebih ditingkatkan lagi.

\section{Ucapan Terima Kasih}

Penulis mengucapkan banyak terima kasih kepada pembimbing utama, yaitu Lusia Safitri Setyo Utami, S.Sos., M.Si. dan kepada responden penelitian, keluarga, adik-adik, teman peneliti, serta seluruh pihak yang telah membantu dan memberikan dukungan. 
Felicia Herlyana, Lusia Savitri Setyo Utami: Pengaruh Daya Tarik Iklan di Konvergensi Media Terhadap Brand Awareness (Studi Iklan Tiket.com di YouTube Pada Kalangan Generasi Z di Jakarta)

\section{Daftar Pustaka}

Awareness Ramayana di Jakarta. Prologia, 2 (2), 422-425. Agustus 24, 2019.

Terarsip di https://journal.untar.ac.id/index.php/prologia/article/view/3722

Haryanto, Agus Tri. (2019, Maret 10). Riset Januari 2019: WhatsApp Digilai Netizen Indonesia. September 11, 2019. Detik.com database.

https://inet.detik.com/cyberlife/d-4461246/riset-januari-2019-whatsapp-digilainetizen-indonesia

Jennifer \& Sari. (2018). Pengaruh Iklan Versi "Nyalakan Harapan” Terhadap Brand.

Legasari, Indarti \& Restuti. (2013). Pengaruh Daya Tarik Iklan, Kreativitas Iklan dan

Kredibilitas Endorser Terhadap Efektivitas Iklan dan Sikap Konsumen Pada Sabun Pemutih Wajah Merek Oil Of Olay di Kota Pekanbaru. Jurnal Ekonomi, 3 (21), 1-15. September 20, 2019. Terarsip di: https://je.ejournal.unri.ac.id/index.php/JE/article/view/1740

Morissan. (2012). Periklanan: Komunikasi Pemasaran Terpadu. Jakarta: Prenada Media Group.

Nasrullah, Rulli. (2017). Media Sosial Perspektif Komunikasi, Budaya dan Sosioteknologi. Bandung: Simbiosa Rekatama Media.

Priansa, Donni Juni. (2017). Komunikasi Pemasaran Terpadu Pada Era Media Sosial. Bandung: CV Pustaka Setia.

Romli, Khomsah Rail. (2016). Komunikasi Massa. Jakarta: PT Grasindo.

Utami dan Hanum. (2018). Analisis Faktor-faktor yang Mempengaruhi Word of Mouth Mahasiswa Unimus. Prosiding Seminar Nasional Unimus 2010. Terarsip di : https://jurnal.unimus.ac.id/index.php/psn12012010/article/view/108/89 